\title{
The Impact of Hypertension on Patients with Acute Coronary Syndromes
}

\author{
Claudio Picariello, Chiara Lazzeri, Paola Attanà, Marco Chiostri, \\ Gian Franco Gensini, and Serafina Valente
}

Intensive Cardiac Care Unit, Careggi Hospital, Viale Morgagni 85, 50184 Florence, Italy

Correspondence should be addressed to Claudio Picariello, claudx@gmail.com

Received 11 February 2011; Revised 15 April 2011; Accepted 19 April 2011

Academic Editor: Amgad N. Makaryus

Copyright (C) 2011 Claudio Picariello et al. This is an open access article distributed under the Creative Commons Attribution License, which permits unrestricted use, distribution, and reproduction in any medium, provided the original work is properly cited.

Arterial chronic hypertension (HTN) is a well-known cardiovascular risk factor for development of atherosclerosis. In order to explain the relation between HTN and acute coronary syndromes the following factors should be considered: (1) risk factors are shared by the diseases, such as genetic risk, insulin resistance, sympathetic hyperactivity, and vasoactive substances (i.e., angiotensin II); (2) hypertension is associated with the development of atherosclerosis (which in turn contributes to progression of myocardial infarction). From all the registries and the data available up to now, hypertensive patients with ACS are more likely to be older, female, of nonwhite ethnicity, and having a higher prevalence of comorbidities. Data on the prognostic role of a preexisting hypertensive state in ACS patients are so far contrasting. The aim of the present paper is to focus on hypertensive patients with ACS, in order to better elucidate whether these patients are at higher risk and deserve a tailored approach for management and followup.

\section{Introduction}

Arterial chronic hypertension (HTN) is one of the established cardiovascular risk factors for development of atherosclerosis [1] and an increased incidence of peripheral vascular disease [2], cerebrovascular disease [3], chronic renal disease [4], and coronary artery disease [5]. It is also an important risk factor for heart failure, myocardial infarction, stroke, and cardiovascular death $[6,7]$.

In patients with acute myocardial infarction (AMI), the prevalence of antecedent hypertension varies from 31 to $59 \%[8,9]$. According to the available evidence, it is not clear whether previously known hypertensive patients have an increased rate of adverse outcomes after AMI including stroke, heart failure, and cardiovascular death [10]. Conversely, in non-ST elevation acute myocardial infarction (NSTEMI), HTN is an independent factor for major shortand long-term cardiac adverse outcome [11].

So far, data on long-term prognostic impact of hypertension in patients with acute coronary syndrome (including ST-elevation myocardial infarction (STEMI), NSTEMI, and unstable angina) are still controversial, and scarce data are available up to now. The aim of the present paper is to focus on hypertensive patients with ACS, in order to better elucidate whether these patients are at higher risk and deserve a tailored approach for management and followup.

\section{Epidemiology and Prevalence of HTN in Patients with Acute Coronary Syndromes}

Arterial hypertension is one of the main factors leading to atherogenesis and the development of vulnerable plaques whose instability or rupture (which in turn results in thrombosis and vessel occlusions) are responsible for the development of acute coronary syndromes (ACS).

In the general population, the prevalence of hypertension rises progressively with age in both men and women, but it is higher at all ages in blacks in whom it is a stronger risk factor for coronary artery disease in respect to whites. About 54\% of the United States population aged 65 to 74 years is hypertensive while among blacks the prevalence 
of hypertension is $72 \%$ [12]. The age- and sex-adjusted prevalence of hypertension (at the $140 / 90 \mathrm{~mm} \mathrm{Hg}$ threshold) is $28 \%$ in the North American countries and $44 \%$ in the European countries [13].

In GUSTO-1 trial, 41021 STEMI patients who presented within 6 hours of symptom onset were randomized to receive different thrombolytic regimens: in this population the prevalence of a history of previous hypertension was 38.1\% (15544 of 41021) [14]. In the GISSI-2 (Gruppo Italiano per lo Studio della Streptochinasi nell'Infarto) which included 20491 patients with STEMI randomized to a $2 \times 2$ protocol of thrombolysis, a history of HTN was present in about $35 \%$ of the whole population [15]. However, to date, the prevalence of arterial hypertension in patients with acute myocardial infarction (AMI) has not been adequately investigated, since most data were obtained from studies performed in the prefibrinolytic era (when drugs such as aspirin, statins, or beta-blockers were not yet part of the routine therapeutic list and few diagnostic or interventional procedures were carried out) or from clinical trials in which the patient characteristics differed considerably from those found in routine clinical practice.

More recently, other studies focused on patients with STEMI submitted to primary PCI $[16,17]$ in which a previous history of hypertension was present in a range of $30-33 \%$. The SYMPHONY trial [18] showed a prevalence of HTN in STEMI patients of more than 50\% (probably due to different criteria of selection of the study population), and a recent Spanish registry (PRIMVAC) reported a $46 \%$ prevalence of hypertension in STEMI patients [19]. Similarly, in a recent paper by our group, performed in 856 STEMI patients all submitted to primary PCI, a previous history of hypertension was detectable in $50.6 \%$ (median age 67 years) [20].

From all the registries and the data available up to now [12-20], hypertensive patients with STEMI are more likely to be older, female, of non-white ethnicity, and having a higher prevalence of comorbidities such as diabetes, hypercholesterolemia, chronic renal failure, history of cardiac heart failure, prior myocardial infarction, and prior myocardial revascularization (angioplasty and stent implantation or coronary artery bypass graft) [21].

In epidemiological studies performed in non-ST elevation myocardial infarction (NSTEMI) patients, chronic HTN is the most prevalent risk factor being detectable in almost two thirds of entire population [22]. This higher prevalence of HTN in NSTEMI in respect to STEMI patients (about $70-75 \%$ versus $30-40 \%$ ) could be justified by the fact that NSTEMI patients are usually older and affected by more comorbidities in respect to STEMI patients.

\section{Hypertension in STEMI: Main Pathophysiologic Mechanisms}

The relation between HTN and myocardial infarction can be mainly explained underscoring two key factors: (1) common risk factors shared by the two diseases, such as genetic risk profiles, insulin resistance, sympathetic hyperactivity, and vasoactive substances (i.e., angiotensin II) and (2) hypertension is associated with accelerated atherosclerosis, which contributes to progression of myocardial infarction [23] (Figure 1). Genetic risk factors, specifically gene polymorphisms of the angiotensinogen-converting enzyme (ACE) and of the renin-angiotensin-aldosterone system (RAS), could represent a "common milieu" responsible for both hypertension and myocardial infarction, in a specific subset of patients at high risk for cardiovascular complications $[24,25]$.

Insulin resistance is another risk factor: [26] hyperinsulinemia is known to contribute to development of both atherosclerosis and hypertension. In fact, decreased effect of insulin on vascular smooth muscle tissue may result in decreased ability to modulate vascular smooth muscle cytoplasmic calcium and enhanced contractility (the socalled "insulin resistance-induced hypertension"). Hyperinsulinemia can also promote atherosclerosis and vascular remodeling: in insulin-resistant patients the left ventricular mass index is greater and the intimal-medial complex of the common carotid artery and the frequency of plaques in carotid artery are higher. In a recent study by our group in 253 nondiabetic STEMI patients submitted to percutaneous coronary intervention, acute insulin resistance, as assessed by HOMA index, was quite common and helped in the early prognostic stratification, as it represented an independent predictor of in-hospital mortality [27]: in this series $47.2 \%$ of patients had a history of HTN on admission.

Furthermore, in hypertensive patients, an hyperactivity of sympathetic tone may promote atherosclerosis by worsening insulin resistance, through sympathetic vasoconstriction on glucose extraction in skeletal muscle, betaadrenoreceptor-mediated insulin resistance, and vascular rarefaction because of the closure of the smaller vessels due to vascular hypertrophy. Sympathetic hyperactivity itself also contributes to a higher risk of sudden death, coronary spasm, and coronary thrombosis [28].

The role of vasoactive substances, such as angiotensin II, endothelin, natriuretic peptides, and nitric oxide, in hypertensive patients is still under debate. Recent researches underscored the role of vascular, local produced angiotensin II, in opposition to its circulating form, in remodeling of vascular structures such as aortic wall in animal models [29]. One of the main factors leading to the development of atherosclerosis in hypertensive patients' vessels is mechanical stress. It consists of three-dimensional forces: shear stress, transmural pressure, and wall stress. Shear stress has been shown to be responsible for the activation of angiotensin II in HTN patients since cultured endothelial cells exposed to shear stress have a higher expression of ACE gene. Transmural pressure produces a "net effect of pressure" on endothelial cells in vitro (in lack of other forces) and vascular smooth cells, thus enhancing the production and growth of new smooth cells. Lastly, stretch stress or wall stress, in cultured vascular smooth muscle cells, can increase the release of factors stimulating the DNA and protein synthesis; stretched smooth cells in turn induce ACE activity and cell growth, finally causing a muscle cell hypertrophy [30]. 


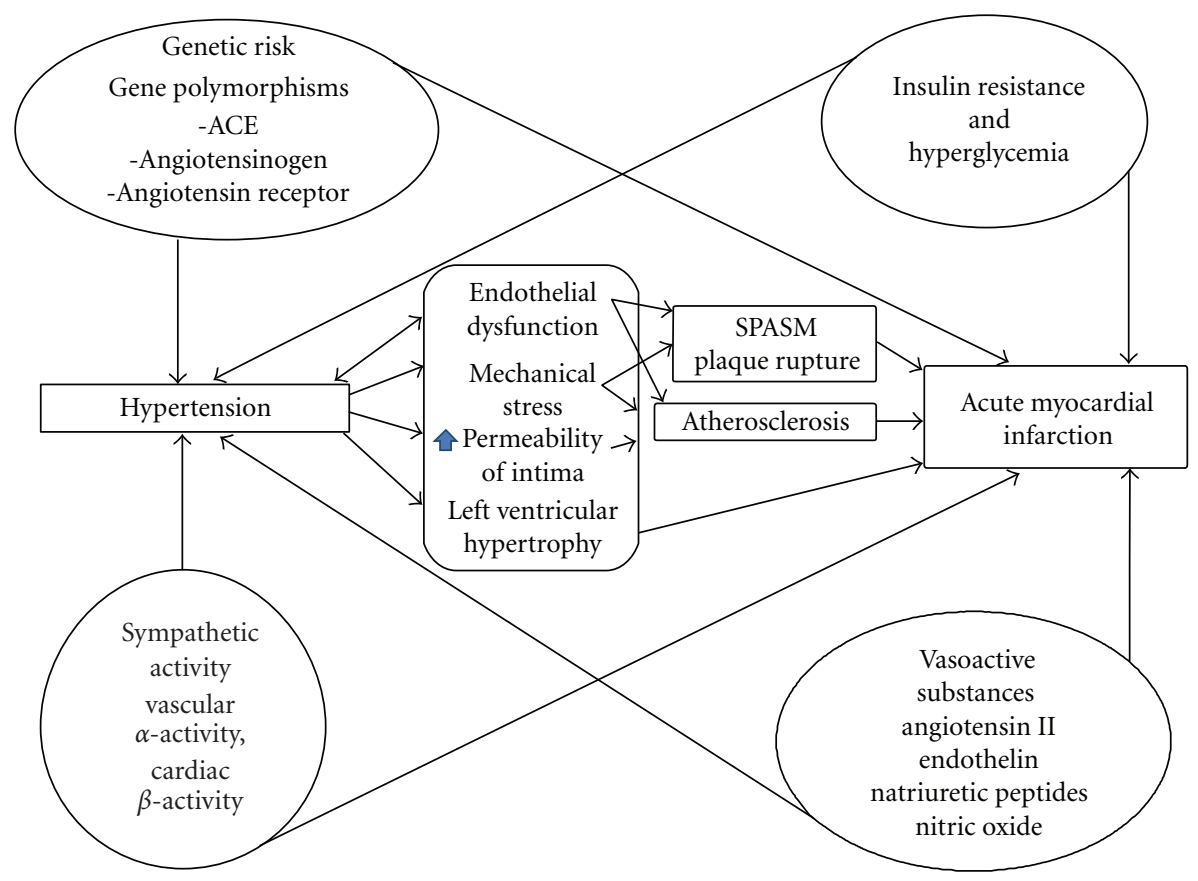

FIgURE 1: Pathophysiological factors that link hypertension and acute myocardial infarction.

A chronic hypertensive state causes cardiac hypertrophy which is an independent risk factor for myocardial infarction. Left ventricular hypertrophy is associated with increased oxygen demand leading to the development of new arterial vessels (collaterals) to supply the myocardium. This collateral circulation, driven by pressure gradient, is more effective in the subepicardial layer than in subendocardial layer, which therefore results in being more exposed to ischemia and infarction. During an acute coronary ischemic event, systolic blood pressure and decreased wall tension of ischemic area result in patency of small vessels, giving some blood supply to the ischemic area. On the other side, large reduction of diastolic blood pressure more often leads to ischemia, despite the lack of total vessel occlusion [31].

Lastly, hypertensive state is characterized by hemorheological abnormalities, such as hyperviscosity, endothelial dysfunction, and a prothrombotic state [32]; moreover it has been demonstrated that vascular inflammation as well as oxidative stress is more prevalent in HTN patients $[33,34]$.

\section{Hypertension in STEMI: The Occurrence of Complications}

The clinical course of STEMI can be affected by several complications, including (1) renal failure, due both to contrast induced nephropathy and acute heart failure, (2) cardiogenic shock, (3) major and minor bleedings causing a new anemic state, and (4) acute glucose imbalance.

Regarding acute renal failure, in a recent paper by Rembek et al. [35] comparing hypertensive and nonhypertensive patients with STEMI, the hypertensive group showed a higher incidence of previous renal diseases such as nephrolithiasis and chronic glomerulonephritis and higher baseline values of urea and creatinine serum level. Al Suwaidi et al. [36] showed that reduced creatinine clearance was a significant adverse prognostic factor for mortality, including cardiovascular deaths, in hypertensive STEMI patients, while Anavekar et al. [37] showed that moderate renal dysfunction (predicted by glomerular filtration rate) was associated with a higher rate of MI complications, in particular heart failure. It is likely that STEMI hypertensive patients are more prone to develop a acute renal failure or a contrast induced nephropathy. A recent study by Thiele et al. [38] confirmed that in both hypertensive and nonhypertensive STEMI patients, who undergo coronary angiography and angioplasty with stenting and moderate doses of contrast medium, only optimal hydration is effective in preventing a contrast-induced nephropathy, while $\mathrm{N}$-acetylcysteine only reduces oxidative stress due to reperfusion after AMI in comparison with placebo [39]. It can be supposed that the target mean arterial pressure in hypertensive patients should be achieved in order to guarantee an adequate renal perfusion and to prevent acute renal failure.

Cardiogenic shock remains the leading cause of death in patients hospitalized with acute MI and in particular with STEMI $[40,41]$, but its incidence has been greatly reduced by the use of reperfusion therapy through mechanical revascularization. One of the wider registries including cardiogenic shock patients, the SHOCK Trial, included 1190 patients from different countries, of which about $53 \%$ had a previous history of hypertension: overall mortality was decreased in comparison with previous registries, and the main cause was ventricular septum rupture [42]. These data agree with our experience in patients with cardiogenic shock treated with IABP (hypertension was detectable in $51.3 \%$ of the entire 
population) [43]. Free wall and interventricular septum ruptures occur more frequently in elderly patients of female sex, in previously known hypertensive patients [44] and in those who suffer from their first acute myocardial infarction, with a preferential involvement of left ventricle and anterior wall at the junction of the infarct and normal muscle. Partial or total rupture of a papillary muscle is more rare but often fatal and can be caused by an inferior wall infarction with involvement of posteromedial papillary muscle: partial rupture (tip or head of muscle) causes a massive but not immediately fatal mitral regurgitation (MR) while total rupture can lead to death (acute massive MR). In all these conditions, especially in patients with previously known and poorly controlled hypertensive state, high blood pressure values could play a pivotal role as they highly increase intracavitary pressures and shear stress force of muscular contraction against an inert and necrotic area, leading to laceration and then to rupture [45]. This strengthens the importance of a strict blood pressure control, in the first hours after an acute myocardial infarction. Specific data on the rate of hemodynamic and bioelectric complications of an acute MI in hypertensive patients are scarce and inconsistent. Mauri et al. [46] have reported that a history of hypertension in AMI was associated with an increased incidence of sudden death. On the other hand, Abrignani et al. [47] found a lower incidence of shock, ventricular fibrillation, atrioventricular conduction disturbances, intracardiac thrombus, and cardiac rupture in hypertensive patients suffering from STEMI, while atrial fibrillation was more common in these patients. More recently, in the paper by Rembek et al., hypertensive STEMI patients showed higher incidence of cardiogenic shock, pulmonary oedema, ventricular tachycardia and/or fibrillation and third degree atrioventricular block; they required intraaortic balloon counterpulsation (IABP) more than nonhypertensive STEMI patients [35].

Our group recently evaluated [48] the role of prior and new anaemia and their prognostic significance in the short term in STEMI patients. Hypertension was present in 53\% of patients, and "new anemia" patients were more frequently affected by hypertension $(56.5 \%)$, followed by prior anemia $(55.3 \%, P<.05)$ and normal $\mathrm{Hb}(46.2 \%, P<.05)$. This strongly suggests that hypertensive STEMI patients are a "high-risk" population with a higher risk of developing bleeding complications and a higher mortality rate.

Lastly, hypertensive patients with STEMI are more likely to be affected by type 2 diabetes [35], and, if without previously known diabetes, they show elevated blood glucose levels on admission, which is known to negatively affect prognosis. In a recent study by Lazzeri et al. [49] on elderly STEMI patients ( $>75$ years), increased glucose values were independent predictors of early death. Prevalence of hypertension was $71 \%$ in females and $65.2 \%$ in males, respectively. A subanalysis of the Acute Myocardial Infarction Registry (KAMIR), which collected a total of 8568 Korean patients with STEMI, confirmed that presence of type 2 diabetes in hypertensive STEMI patients is very common and is associated with worse clinical and angiographic features with a higher risk to develop heart failure and an increased risk of MACE on long-term followup [50].

\section{Hypertension in STEMI: Prognosis}

Several studies reported that a history of hypertension was associated with an increased rate of adverse outcomes after AMI such as stroke, heart failure, and cardiovascular death $[6,10]$. The increased incidence of AMI or sudden death in hypertensive patients may be related to several factors, such as endothelial damage, atherosclerosis, insulin resistance, left ventricular hypertrophy, and ventricular arrhythmias [23]. In the KAMIR study $48 \%$ of STEMI patients had hypertension: at multivariate analysis a history of hypertension independently contributed to higher in-hospital mortality in patients with AMI but not to one-year mortality. This was related not to antecedent hypertension but to the coexistence of other risk factors (old age, high Killip class, multivessel disease) [51]. Multivessel disease and complex lesions in coronary angiography are among the factors which have been proved to be associated with poor outcomes in hypertensive patients [52].

In the GISSI-2 study, in-hospital and 6-month mortality in hypertensive MI patients was significantly higher compared to normotensive patients [15] as was the rate of left ventricular failure, recurrent angina, and recurrent MI. On the other hand, GUSTO-1 study showed that elevated blood pressure was not an independent prognostic factor for 30day mortality, but in these trial patients with very high values of blood pressure were excluded due to the thrombolytic treatment [14]. A later subanalysis of the GUSTO-1 trial [53] found a higher risk of early death in patients with elevated systolic blood pressure (BP) at admission.

On the other side, Abrignani et al. [47] stated that hypertensive subjects with first AMI have a better in-hospital outcome than age- and gender-matched normotensive subjects, perhaps due to a less severe extension of the infarction area or to a different physiopathologic mechanism. Other studies did not show relevant difference for in-hospital and 6-month mortality in hypertensive and normotensive patients with myocardial infarction $[35,54]$, even considering different subgroups according to BP admission values (normal, highnormal, high) [55].

In the PROVE-IT-TIMI 22 trial (PRavastatin Or atorVastatin Evaluation and Infection Therapy-Thrombolysis in Myocardial Infarction) 4162 patients with ACS were categorized in $10 \mathrm{~mm} \mathrm{Hg}$ increments of blood pressure during followup: a J- or U-shaped curve association was found between blood pressure and risk of future cardiovascular events, with the lowest event rates in the systolic pressure (SBP) range of 130 to $140 \mathrm{~mm} \mathrm{Hg}$ and 80 to $90 \mathrm{~mm} \mathrm{Hg}$ diastolic pressure (DBP), a flat curve for $110-130 \mathrm{~mm} \mathrm{Hg}$ SBP and $70-90 \mathrm{~mm} \mathrm{Hg}$ BDP. The latter finding strongly suggests that too low pressures (especially $<110 / 70 \mathrm{~mm}$ $\mathrm{Hg}$ ) may be dangerous; anyway the trial considered only blood pressure values during follow-up visits, not in-hospital measurements [56].

Most of the studies regarding links between hypertension and myocardial infarction consider patients with a previous history of hypertension, but few data are available about patients who do not have a previously known history of hypertension but showed elevated blood pressure values 
during their hospital staying for ACS. In patients with myocardial infarction admitted within 6 hours from the onset of pain [57], 31.7\% presented with elevated blood pressure $(\geq 160 / 100 \mathrm{~mm} \mathrm{Hg})$ : only $6.3 \%$ of these patients had elevated blood pressure levels after 6 hours, though not treated with any antihypertensive drug. Blood pressure should therefore be carefully monitored in patients with ACS for several reasons: (a) to achieve the optimal perfusion pressure by tailoring drugs, (b) to prevent complications (ranging from drug-induced hypotension to hypertensive crisis which may promote acute heart failure syndrome), and (c) to obtain renal protection (thus preventing acute renal failure). Whenever the findings of serial high BP measurements and/or previously not known left ventricular hypertrophy should lead to the suspicion that a hypertensive state was present before hospital admission for ACS, a more strict followup should be recommended in these patients as well as investigations in order to rule out hypertensionrelated complications (i.e., fundus oculi).

\section{Recommendations}

(1) ACS patients with hypertension represent a subset at higher risk since they are more often older and with higher comorbidities (including renal failure).

(2) In these patients blood pressure values should be carefully monitored in order to achieve an adequate perfusion pressure (usually values of mean arterial pressure higher in respect to nonhypertensive ACS patients). The main goal is to prevent renal failure due to hypoperfusion.

(3) At echocardiographic evaluation, diastolic function should be carefully assessed and treated in hypertensive ACS patients. In these patients, hypertensive crises can lead to the development of acute heart failure syndrome.

(4) Comorbidities should be "searched" if not previously diagnosed, firstly, glucose imbalance by means of serial glucose measurements, acute insulin resistance (by means of HOMA index), and glycated haemoglobin (indicating the glucose control in the previous months). The occurrence of anemia on admission should induce an accurate evaluation of renal function in order to exclude the coexistence of renal failure.

(5) In presence of BP values difficult to treat, stenosis of renal artery should be ruled out.

(6) A strict followup should be recommended in ACS patients with hypertension with close monitoring of adherence to drug administration. In fact, polypharmacy is quite frequent in hypertensive patients, especially after ACS, but in these patients the consequences of drug discontinuation may be severe and even lethal.

\section{References}

[1] V. J. Dzau, "Atherosclerosis and hypertension: mechanisms and interrelationships," Journal of Cardiovascular Pharmacology, vol. 15, supplement 5, pp. S59-S64, 1990.

[2] J. M. Murabito, R. B. D’Agostino, H. Silbershatz, and P. W. F. Wilson, "Intermittent claudication: a risk profile from the Framingham Heart Study," Circulation, vol. 96, no. 1, pp. 4449, 1997.

[3] S. Lewington, R. Clarke, N. Qizilbash, R. Peto, and R. Collins, "Age-specific relevance of usual blood pressure to vascular mortality: a meta-analysis of individual data for one million adults in 61 prospective studies," Lancet, vol. 360, no. 9349, pp. 1903-1913, 2002, Erratum in: Lancet, vol. 361, no. 9362, p. $106,2003$.

[4] M. Adamczak, M. Zeier, R. Dikow, and E. Ritz, "Kidney and hypertension," Kidney International, Supplement, vol. 61, no. 80, pp. S62-S67, 2002.

[5] D. Levy, P. W. F. Wilson, K. M. Anderson, and W. P. Castelli, "Stratifying the patient at risk from coronary disease: new insights from the Framingham Heart Study," American Heart Journal, vol. 119, no. 3, part 2, pp. 712-717, 1990.

[6] A. M. Richards, M. G. Nicholls, R. W. Troughton et al., "Antecedent hypertension and heart failure after myocardial infarction," Journal of the American College of Cardiology, vol. 39, no. 7, pp. 1182-1188, 2002.

[7] K. Miura, M. L. Daviglus, A. R. Dyer et al., "Relationship of blood pressure to 25-year mortality due to coronary heart disease, cardiovascular diseases, and all causes in young adult men: the chicago heart association detection project in industry," Archives of Internal Medicine, vol. 161, no. 12, pp. 1501-1508, 2001.

[8] S. N. Willich, J. Müller-Nordhorn, M. Kulig et al., "Cardiac risk factors, medication, and recurrent clinical events after acute coronary disease: a prospective cohort study," European Heart Journal, vol. 22, no. 4, pp. 307-313, 2001.

[9] P. S. Yusuf, S. Hawken, S. Ônpuu et al., "Effect of potentially modifiable risk factors associated with myocardial infarction in 52 countries (the INTERHEART study): case-control study," Lancet, vol. 364, no. 9438, pp. 937-952, 2004.

[10] J. J. Thune, J. Signorovitch, L. Kober et al., "Effect of antecedent hypertension and follow-up blood pressure on outcomes after high-risk myocardial infarction," Hypertension, vol. 51, no. 1, pp. 48-54, 2008.

[11] R. Dumaine, C. M. Gibson, S. A. Murphy et al., "Association of a history of systemic hypertension with mortality, thrombotic, and bleeding complications following non-STsegment elevation acute coronary syndrome," Journal of Clinical Hypertension, vol. 8, no. 5, pp. 315-322, 2006.

[12] V. L. Burt, P. Whelton, E. J. Roccella et al., "Prevalence of hypertension in the US adult population: results from the third National Health and Nutrition Examination Survey, 1988-1991," Hypertension, vol. 25, no. 3, pp. 305-313, 1995.

[13] K. Wolf-Maier, R. S. Cooper, J. R. Banegas et al., "Hypertension prevalence and blood pressure levels in 6 European countries, Canada, and the United States," Journal of the American Medical Association, vol. 289, no. 18, pp. 2363-2369, 2003.

[14] E. Topol, R. Califf, F. Van de Werf et al., "An international randomized trial comparing four thrombolytic strategies for acute myocardial infarction," New England Journal of Medicine, vol. 329, no. 10, pp. 673-682, 1993.

[15] C. Fresco, F. Avanzini, S. Bosi et al., "Prognostic value of a history of hypertension in 11,483 patients with acute myocardial infarction treated with thrombolysis. GISSI-2 Investigators. 
Gruppo Italiano per lo Studio della, Sopravvivena nell'Infarto Miocardico," Journal of Hypertension, vol. 14, no. 6, pp. 743 $750,1996$.

[16] A. El-Menyar, M. Zubaid, A. Shehab et al., "Prevalence and impact of cardiovascular risk factors among patients presenting with acute coronary syndrome in the middle east," Clinical Cardiology, vol. 34, no. 1, pp. 51-58, 2011.

[17] W. M. Ali, M. Zubaid, A. El-Menyar et al., "The prevalence and outcome of hypertension in patients with acute coronary syndrome in six Middle-Eastern countries," Blood Pressure, vol. 20, no. 1, pp. 20-26, 2011.

[18] C. G. Frazier, S. H. Shah, P. W. Armstrong et al., "Prevalence and management of hypertension in acute coronary syndrome patients varies by sex: observations from the Sibrafiban versus aspirin to Yield Maximum Protection from ischemic Heart events postacute cOroNary sYndromes (SYMPHONY) randomized clinical trials," American Heart Journal, vol. 150, no. 6, pp. 1260-1267, 2005.

[19] V. Bertomeu, A. Cabadés, P. Morillas et al., "Clinical course of acute myocardial infarction in the hypertensive patient in Eastern Spain: the PRIMVAC registry," Heart and Lung: Journal of Acute and Critical Care, vol. 35, no. 1, pp. 20-26, 2006.

[20] C. Lazzeri, S. Valente, M. Chiostri, C. Picariello, and G. F. Gensini, "Uric acid in the early risk stratification of ST-elevation myocardial infarction," Internal and Emergency Medicine, 2011.

[21] F. D’Ascenzo, A. Gonella, G. Quadri et al., "Comparison of mortality rates in women versus men presenting with STsegment elevation myocardial infarction," American Journal of Cardiology, vol. 107, no. 5, pp. 651-654, 2011.

[22] D. Hasdai, S. Behar, L. Wallentin et al., "A prospective survey of the characteristics, treatments and outcomes of patients with acute coronary syndromes in Europe and the Mediterranean basin: the Euro Heart Survey of Acute Coronary Syndromes (Euro Heart Survey ACS)," European Heart Journal, vol. 23, no. 15, pp. 1190-1201, 2002.

[23] H. Rakugi, H. Yu, A. Kamitani et al., "Links between hypertension and myocardial infarction," American Heart Journal, vol. 132, no. 1, part 2, pp. 213-221, 1996.

[24] A. Hata, C. Namikawa, M. Sasaki et al., "Angiotensinogen as a risk factor for essential hypertension in Japan," Journal of Clinical Investigation, vol. 93, no. 3, pp. 1285-1287, 1994.

[25] N. Iwai, H. Shimoike, N. Ohmichi, and M. Kinoshita, "Angiotensinogen gene and blood pressure in the Japanese population," Hypertension, vol. 25, no. 4, part 2, pp. 688-693, 1995.

[26] J. R. Sowers, P. R. Standley, J. L. Ram, S. Jacober, L. Simpson, and K. Rose, "Hyperinsulinemia, insulin resistance, and hyperglycemia: contributing factors in the pathogenesis of hypertension and atherosclerosis," American Journal of Hypertension, vol. 6, no. 7, part 2, pp. 260S-270S, 1993.

[27] C. Lazzeri, A. Sori, M. Chiostri, G. F. Gensini, and S. Valente, "Prognostic role of insulin resistance as assessed by homeostatic model assessment index in the acute phase of myocardial infarction in nondiabetic patients submitted to percutaneous coronary intervention," European Journal of Anaesthesiology, vol. 26, no. 10, pp. 856-862, 2009.

[28] S. Julius, "Sympathetic hyperactivity and coronary risk in hypertension," Hypertension, vol. 21, no. 6, part 2, pp. 886 893, 1993.

[29] V. J. Dzau and R. Re, "Tissue angiotensin system in cardiovascular medicine: a paradigm shift?” Circulation, vol. 89, no. 1, pp. 493-498, 1994.
[30] M. Ohishi, H. Rakugi, T. Ogihara, H. Schunkert, H. W. Hense, and G. A. J. Riegger, "Association between a deletion polymorphism of the angiotensin-converting-enzyme gene and left ventricular hypertrophy," New England Journal of Medicine, vol. 331, no. 16, pp. 1097-1098, 1994.

[31] E. Casiglia, A. Mazza, V. Tikhonoff et al., "Weak effect of hypertension and other classic risk factors in the elderly who have already paid their toll," Journal of Human Hypertension, vol. 16, no. 1, pp. 21-31, 2002.

[32] G. Y. H. Lip, D. C. Felmeden, F. L. Li-Saw-Hee, and D. G. Beevers, "Hypertensive heart disease: a complex syndrome or a hypertensive 'cardiomyopathy'?" European Heart Journal, vol. 21, no. 20, pp. 1653-1665, 2000.

[33] H. D. Sesso, J. E. Buring, N. Rifai, G. J. Blake, J. M. Gaziano, and P. M. Ridker, "C-reactive protein and the risk of developing hypertension," Journal of the American Medical Association, vol. 290, no. 22, pp. 2945-2951, 2003.

[34] J. Redón, M. R. Oliva, C. Tormos et al., "Antioxidant activities and oxidative stress byproducts in human hypertension," Hypertension, vol. 41, no. 5, pp. 1096-1101, 2003.

[35] M. Rembek, A. Goch, and J. Goch, "The clinical course of acute ST-elevation myocardial infarction in patients with hypertension," Kardiologia Polska, vol. 68, no. 2, pp. 157-163, 2010.

[36] J. Al Suwaidi, D. N. Reddan, K. Williams et al., "Prognostic implications of abnormalities in renal function in patients with acute coronary syndromes," Circulation, vol. 106, no. 8, pp. 974-980, 2002.

[37] N. S. Anavekar, J. J. V. McMurray, E. J. Velazquez et al., "Relation between renal dysfunction and cardiovascular outcomes after myocardial infarction," New England Journal of Medicine, vol. 351, no. 13, pp. 1285-1295, 2004.

[38] H. Thiele, L. Hildebrand, C. Schirdewahn et al., "Impact of high-dose $\mathrm{N}$-acetylcysteine versus placebo on contrastinduced nephropathy and myocardial reperfusion injury in unselected patients with ST-segment elevation myocardial infarction undergoing primary percutaneous coronary intervention. The LIPSIA-N-ACC (Prospective, Single-Blind, Placebo-Controlled, Randomized Leipzig Immediate PercutaneouS Coronary Intervention Acute Myocardial Infarction NACC) Trial," Journal of the American College of Cardiology, vol. 55, no. 20, pp. 2201-2209, 2010.

[39] S. Valente, C. Lazzeri, C. Giglioli et al., "Contrast-induced nephropathy in urgent coronary interventions," Journal of Cardiovascular Medicine, vol. 7, no. 10, pp. 737-741, 2006.

[40] R. C. Becker, J. M. Gore, C. Lambrew et al., "A composite view of cardiac rupture in the United States National Registry of Myocardial Infarction," Journal of the American College of Cardiology, vol. 27, no. 6, pp. 1321-1326, 1996.

[41] S. Valente, C. Lazzeri, S. Vecchio et al., "Predictors of inhospital mortality after percutaneous coronary intervention for cardiogenic shock," International Journal of Cardiology, vol. 114, no. 2, pp. 176-182, 2007.

[42] J. S. Hochman, L. A. Sleeper, J. G. Webb et al., "Early revascularization in acute myocardial infarction complicated by cardiogenic shock," New England Journal of Medicine, vol. 341, no. 9, pp. 625-634, 1999.

[43] S. Valente, C. Lazzeri, M. Chiostri, M. Zucchini, C. Giglioli, and G. F. Gensini, "Intra-aortic balloon pump in intensive cardiac care: a registry in Florence," International Journal of Cardiology, vol. 146, no. 2, pp. 238-239, 2011.

[44] J. Figueras, J. Cortadellas, F. Calvo, and J. Soler-Soler, "Relevance of delayed hospital admission on development of cardiac rupture during acute myocardial infarction: study in 
225 patients with free wall, septal or papillary muscle rupture," Journal of the American College of Cardiology, vol. 32, no. 1, pp. 135-139, 1998.

[45] Y. Birnbaum, A. J. Chamoun, A. Anzuini, S. D. Lick, M. Ahmad, and B. F. Uretsky, "Ventricular free wall rupture following acute myocardial infarction," Coronary Artery Disease, vol. 14, no. 6, pp. 463-470, 2003.

[46] F. Mauri, A. P. Maggioni, M. G. Franzosi et al., "A simple electrocardiographic predictor of the outcome of patients with acute myocardial infarction treated with a thrombolytic agent. A Gruppo Italiano per lo Studio della Sopravvivenza nell'Infarto Miocardico (GISSI-2)-Derived Analysis," Journal of the American College of Cardiology, vol. 24, no. 3, pp. 600607, 1995, Erratum in: Journal of the American College of Cardiology, vol. 25, no. 3, p. 805, 1995.

[47] M. G. Abrignani, L. J. Dominguez, G. Biondo et al., "Inhospital complications of acute myocardial infarction in hypertensive subjects," American Journal of Hypertension, vol. 18, no. 2, part 1, pp. 165-170, 2005.

[48] S. Valente, C. Lazzeri, M. Chiostri, A. Sori, C. Giglioli, and G. F. Gensini, "Prior and new onset anemia in ST-elevation myocardial infarction: a different prognostic role?" Internal and Emergency Medicine, 2010.

[49] C. Lazzeri, S. Valente, M. Chiostri, C. Picariello, and G. F. Gensini, "Predictors of the early outcome in elderly patients with ST elevation myocardial infarction treated with primary angioplasty: a single center experience," Internal and Emergency Medicine, vol. 6, no. 1, pp. 41-46, 2011.

[50] G. L. Min, H. J. Myung, Y. Ahn et al., "Comparison of clinical outcomes following acute myocardial infarctions in hypertensive patients with or without diabetes," Korean Circulation Journal, vol. 39, no. 6, pp. 243-250, 2009.

[51] D. G. Kang, M. H. Jeong, Y. Ahn et al., "Clinical effects of hypertension on the mortality of patients with acute myocardial infarction," Journal of Korean Medical Science, vol. 24, no. 5, pp. 800-806, 2009.

[52] R. B. Devereux and M. J. Roman, "Inter-relationships between hypertension, left ventricular hypertrophy and coronary heart disease," Journal of Hypertension, vol. 11, no. 4, pp. S3-S9, 1993.

[53] P. E. Aylward, R. G. Wilcox, J. H. Horgan et al., "Relation of increased arterial blood pressure to mortality and stroke in the context of contemporary thrombolytic therapy for acute myocardial infarction: a randomized trial," Annals of Internal Medicine, vol. 125, no. 11, pp. 891-900, 1996.

[54] S. K. Majahalme, D. E. Smith, J. V. Cooper et al., "Comparison of patients with acute coronary syndrome with and without systemic hypertension," American Journal of Cardiology, vol. 92, no. 3, pp. 258-263, 2003.

[55] M. Jonas, E. Grossman, V. Boyko, S. Behar, H. Hod, and H. Reicher-Reiss, "Relation of early and one-year outcome after acute myocardial infarction to systemic arterial blood pressure on admission," American Journal of Cardiology, vol. 84, no. 2, pp. 162-165, 1999.

[56] S. Bangalore, J. Qin, S. Sloan, S. A. Murphy, and C. P. Cannon, "What is the optimal blood pressure in patients after acute coronary syndromes?: relationship of blood pressure and cardiovascular events in the pravastatin or atorvastatin evaluation and infection therapy-thrombolysis in myocardial infarction (PROVE IT-TIMI) 22 trial," Circulation, vol. 122, no. 21, pp. 2142-2151, 2010.

[57] T. C. Gibson, "Blood pressure levels in acute myocardial infarction," American Heart Journal, vol. 96, no. 4, pp. 475480, 1978. 


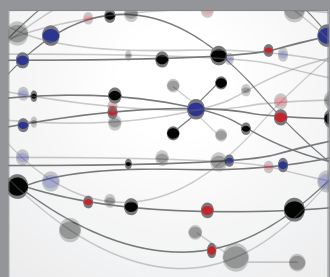

The Scientific World Journal
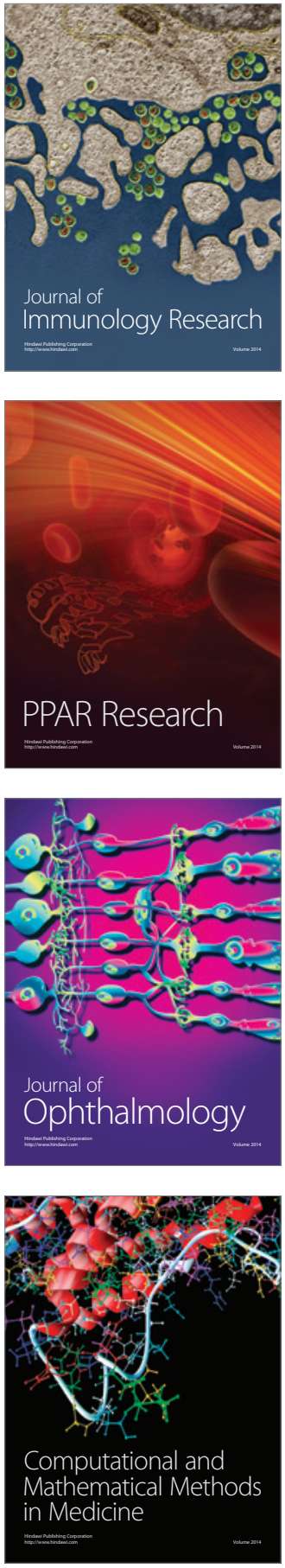

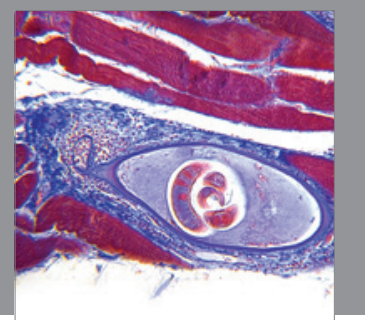

Gastroenterology

Research and Practice
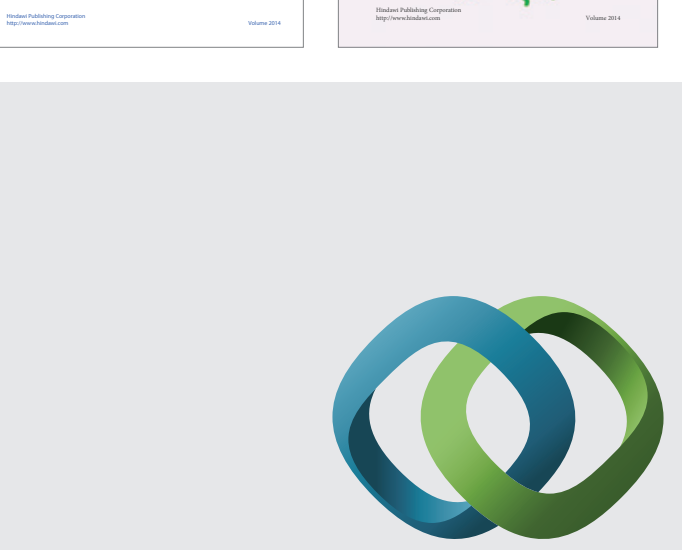

\section{Hindawi}

Submit your manuscripts at

http://www.hindawi.com
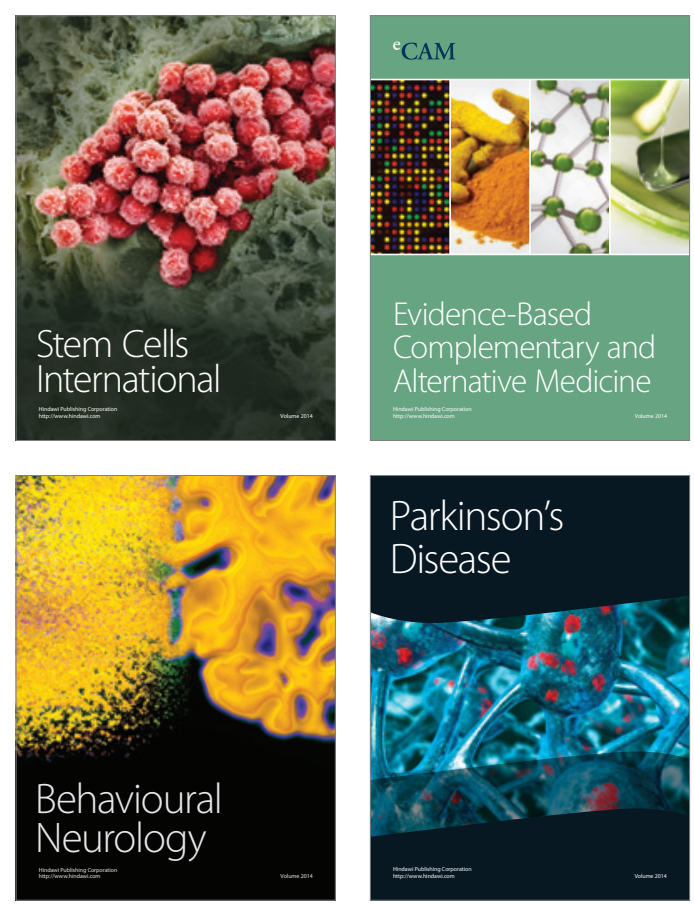

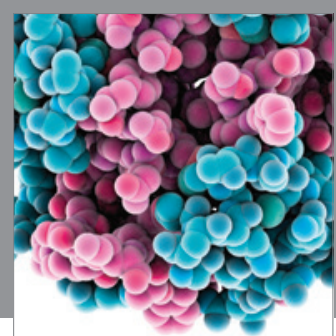

Journal of
Diabetes Research

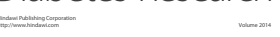

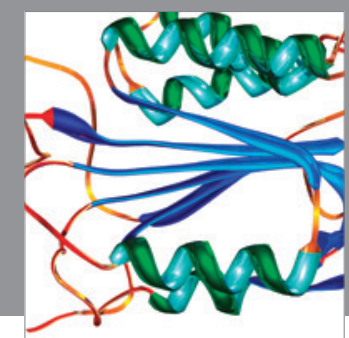

Disease Markers
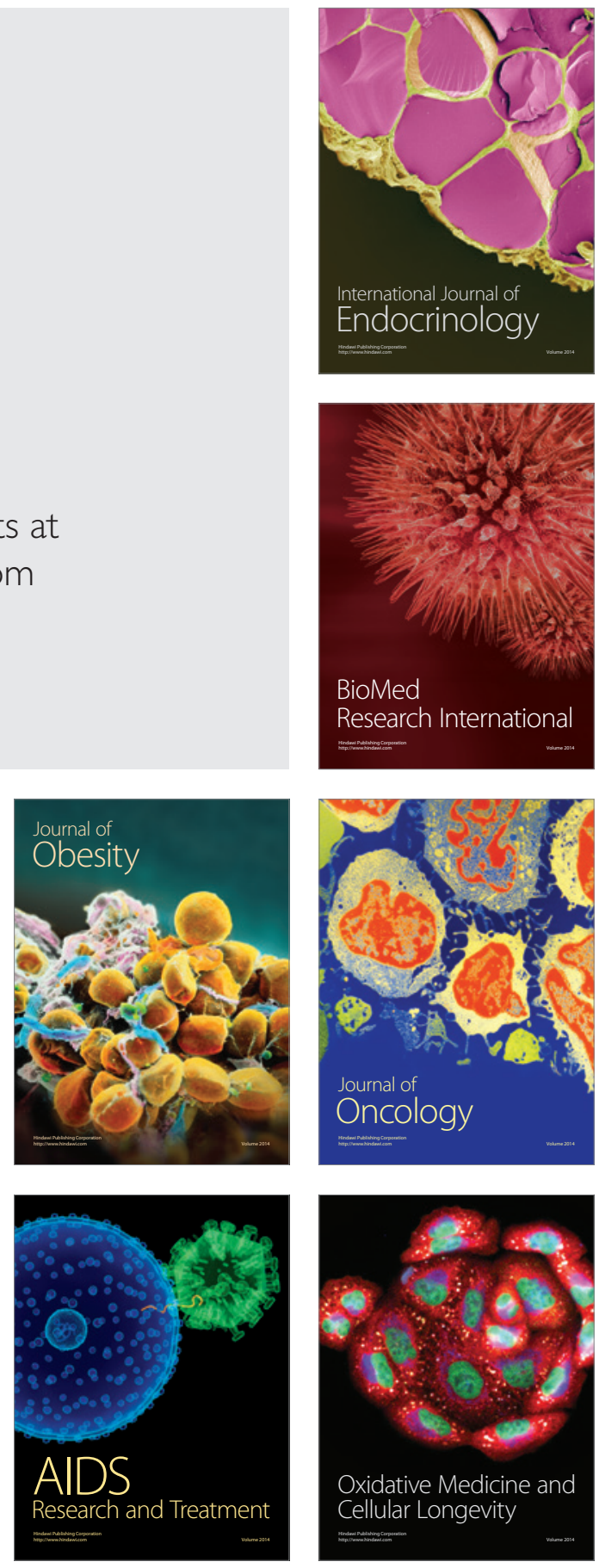